\title{
Pertinências entre os anais egípcios e a biografia antiga: ensaio historiográfico sobre escrita e ideologia nas inscrições cuneiformes e hieroglíficas de eventos oficiais e memoriais do Egito antigo ${ }^{* 1}$
}

\author{
João Batista Ribeiro Santos ${ }^{2}$
}

\section{Resumo}

Este ensaio tem como fontes escritas os anais egípcios, cujo objeto de análise será a representação faraônica na escrita da história. Abordaremos, como objetivo da tarefa historiográfica, os anais e os postulados da biografia com o intuito de desenvolver a hipótese segundo a qual os anais refletem a imagem biográfica faraônica idealizada, mas também contribuir com os novos debates sobre os domínios da história.

Palavras-chave: Escrita da história; Egito antigo; cultura material.

\section{Résumé}

Cette recherche a comme sources écrites les annales égyptiennes, qui ont pour objet l'analyse sera la représentation d'écriture de l'histoire pharaonique. Nous couvrirons, objectif de la tâche historiographique, les annales et les postulats de biographie afin de développer l'hypothèse selon laquelle les annales reflètent l'image idéalisée pharaonique, mais biographiques aussi contribuent avec nouveaux débats sur les champs de l'histoire.

Mots-clés: Écriture de l'histoire; Égypte antique; culture matérielle.

\section{Introdução}

O estudo do passado requer textos de uma larga variedade, artefatos e evidências arqueológicas; consequentemente, a abordagem implica vários domínios disciplinares. Destarte, tempos e lugares diferentes apresentam conclusões divergentes, mesmo em relação a dados gerais na investigação de traços do passado na criação da história (MORRISON, 2009: 6-8). É aceitável “ a ideia de que toda afirmação histórica está associada a um determinado

\footnotetext{
*Artigo submetido em 13 de julho de 2013, e aprovado em 25 de novembro de 2013.

${ }^{1} \mathrm{O}$ primeiro manuscrito desta pesquisa foi realizado no âmbito dos meus estudos de mestrado em História Política na Universidade do Estado do Rio de Janeiro (UERJ) e apresentado à Profa. Dra. Márcia Almeida Gonçalves, a quem dedico. Agradeço, pela concessão de uma bolsa de estudos, à Fundação Carlos Chagas Filho de Amparo à Pesquisa do Estado do Rio de Janeiro (FAPERJ).

${ }^{2}$ Mestre em Ciências da Religião, com linha de pesquisa em "Literatura e religião no mundo bíblico", pela Universidade Metodista de São Paulo (UMESP) e mestre em História Política, com linha de pesquisa em "História Antiga e Medieval", pela Universidade do Estado do Rio de Janeiro (UERJ). Lattes: 0618451218254540. E-mail: jj.batist@gmail.com 
ponto de vista" (KOSELLECK, 2011: 163), não desconsiderando totalmente, ainda que diante da exigência de uma proposição objetiva, a subjetividade como potência nas afirmações e fontes. Assim, uma questão - e com ela uma premissa teórica - surge do fato de algumas fontes epigráficas egípcias serem análogas a fórmulas idealizadoras, portanto de caráter parcial não apenas do ponto de vista historiográfico.

No que diz respeito à premissa, a narração dos eventos e a descrição das estruturas reais quase coincidem na transmissão. Por isso, há pertinência quando Arnaldo Momigliano sugere a possibilidade de haver uma relação especial entre a biografia e os membros do Liceu ateniense na prática historiográfica. Ele questiona a possibilidade da existência de uma escola de biografia peripatética, que se interessa por diversos tipos de personalidades, supondo que Aristóteles seja o fundador da biografia grega (MOMIGLIANO, 1983: 106). Momigliano cita diversos estudos sobre o assunto, menciona quem acredita (por exemplo, Friedrich Leo e Albrecht Dihle) que a Apologia de Platão tenha sido o primeiro modelo de biografia mas que a Ética de Aristóteles tenha exercido uma influência mais predominante sobre os biógrafos posteriores.

La biographie et l'autobiographie ne sont ni antérieures ni postérieures aux autres genres historiques traitant des événements lointains d'un passé récent. La biographie et l'autobiographie furent des genres autonomes dès leur origine et se développèrent parallèlement à l'histoire politique: celle-ci ne les absorba jamais. La distinction entre biographie et histoire (entendons ici l'histoire politique) fut fondée en théorie au cours de la période hellénistique, mais elle existait déjà en fait au $v^{e}$ siècle (MOMIGLIANO, 1983: 118). ${ }^{3}$

Com relação à Antiguidade, nem sempre é possível distinguir quando a narração da história registra realidade ou imaginação, pelo fato de não existir distinção clara e permanente do que é historiografia ou biografia. Com efeito, os anais também não distinguem especificamente instituição e guerra, rei e divindade, desenvolvimento e apropriação, pelo que a distinção não determina o tipo de documento textual, ainda que o autor tenha a possibilidade de apreender a realidade. É aqui que situamos as diferenças e pertinências entre a escrituração da história e a historicização egípcia do fato reconhecidamente documental.

\footnotetext{
3 Tradução: “A biografia e a autobiografia não são nem anteriores nem posteriores a outros gêneros históricos que tratam de eventos distantes de um passado recente. A biografia e a autobiografia foram dois gêneros autônomos em sua origem e desenvolvidos paralelamente com a história política: eles nunca são absorvidos. A distinção entre biografia e história (entendemos aqui a história política) foi fundada na teoria durante o período helenístico, mas na verdade ele já existia no século V a.C.".
} 
Em adição, não ignoramos, como avaliou inicialmente Edoardo Grendi (2009: 42) em relação ao pesquisador da Idade Contemporânea, que "o episódio individual vem de tal modo carregado de valores ideológicos", no âmbito das relevâncias para a escrituração, que torna-se irrelevante como "campo específico de análise". Conforme as lógicas discursivas, ${ }^{4}$ anais e biografia antiga não se dissociam do "querer-dizer"5 pretendido notadamente nos valores ideológicos ambientados, em que a história, por vezes, pode encontrar o presente no seu objeto e encontrar o passado na sua prática. ${ }^{6}$ Este vínculo permite à biografia antiga os contextos da análise dos eventos, respectivamente na reconstrução dos anais.

\section{Sobre a escrita da história}

Segundo Arnaldo Momigliano, por Heródoto, pesquisar a história (istoría) significa tratar de etnografia, instituições e guerra. Tudo que não fazia parte de um desses domínios era chamado comumente de "antichità" (archaiología). O que poder-se-ia procurar na biografia egípcia é o indivíduo por detrás da sociedade descrita através do acontecimento. No caso dos anais faraônicos, o etnógrafo testemunha a sua identidade como um sujeito in eventu. Nos anais está inscrito o $e u$ na forma de narração de acontecimento, mas também na forma de relato institucional com seus desdobramentos políticos.

Em uma sociedade com ocupações qualificadas, evidentemente com os efeitos da mobilidade da vida urbana, mormente quando destinadas à redistribuição demográfica e estratégias para posicionamentos diplomáticos ou geopolíticos com a exacerbação de poderio político-econômico-militar, a ideologia cumpre, por vezes, função material à guisa de identificação, mormente em sociedades estatizadas.

There is evidence that indicates time and space was transcended in the ancient Near East, certainly in the third and second millennia B.C., by an intricate mesh of social structures, political ideologies, religious beliefs, rituals, and other practices, that, whether consciously intended or not, had the effect of binding disparate, and distant, components of the sociopolitical entity into one. This complex of structure, thought, and practice was constitutive of ideologies of kinship - not kinship as pre-existing in actual connections through birth, although they are both present and implicit, but kinship as created and incorporative of networks of social relations no

\footnotetext{
${ }^{4} \mathrm{O}$ emprego de "discurso" como adjetivo está em uma linguagem conceitualmente política porque buscamos abordar o contexto, não apenas o texto (POCOCK, 2003: 63-82).

${ }^{5}$ Cabem particularmente algumas contribuições de François Dosse (2009: 340-359).

${ }^{6}$ Aqui o "fazer história" de Michel de Certeau foi-nos útil, assim como o foi para François Dosse (CERTEAU, 2011: 3-44). 
matter actual birth relations (PORTER, 2009: 202). ${ }^{7}$

Desta forma, propõe-se relacionar a cultura material às estruturas políticas como uma inequívoca consideração metodológica. ${ }^{8}$ Mesmo quando tratar-se de conexão com comunidades de linhagem de parentesco, tecnologicamente menos desenvolvidas e hierarquicamente menos organizadas em relação ao Egito, as inquirições devem explicitar a materialidade, política e ideologicamente, que precede inclusive a trajetória evolucionária social dos metais e as cidades-Estado.

Sob as condições forjadas pelos cruzamentos culturais, no processo de escrituração, a nosso ver, os epigrafistas egípcios dos anais, por inexistirem conceitualmente, à época, "biografia" e "autobiografia" para os registros práticos, catalogaram o gênero literário que trata de instituições, guerras e conquistas, mas também de dados pessoais, projetos de expansão, ação e autoglorificação. Neste sentido, uma definição de história, levando em conta a forma de narração de evento do passado, deve considerar que nem todas as civilizações desenvolveram uma forma intelectual inerente, embora a forma intelectual corresponda ao que se pode denominar escrita da história, que examina o desenvolvimento das histórias nacionais. "Um determinado período do passado é geralmente tomado como início ideal, a era constitutiva, o ponto de partida com base no qual se julgarão os períodos seguintes e se justificarão as atuais circunstâncias da nação" (SETERS, 2008: 20). Argumentativamente, explica-se assim, portanto, as mudanças sociais, estabelecendo as bases para uma nova significação das formas tradicionais e estruturais que estão em vias de transformação, porque "a escrita da história é propriamente nacional ou coletiva. Sendo assim, o simples relato dos feitos de um rei é somente biográfico, a menos que eles sejam encarados como parte da história nacional" (SETERS, 2008: 23).

Os faraós têm em vista a criação de uma imagem divinizada de si mesmos, eles mantêm a esperança de superar o seu antecessor em realizações e, portanto, na grandiosidade legada à dinastia. A descrição de seu espaço é sempre abrangente e as correspondências

\footnotetext{
7 Tradução: "Há evidências que indicam que tempo e espaço foram transcendidos no antigo Oriente-Próximo, certamente nos terceiro e segundo milênios a.C., por uma intrincada malha de estruturas sociais, ideologias políticas, crenças religiosas, rituais e outras práticas, que, destinada a ser conscientemente ou não, teve o efeito de vincular díspares, e distantes, componentes da entidade sociopolítica como se fossem um. Este complexo de estrutura, pensamento e prática era constitutivo de ideologias de parentesco - não parentesco como pré-existente em conexões reais através do nascimento, apesar de estar presente e implícito, mas parentesco como criado e incorporativo das redes de relações sociais, não importando as relações de nascimento real".

${ }^{8}$ Sobre o estudo da cultura material nos procedimentos metodológicos, além do ensaio de Anne Porter (2009), visando a integração metodológica de grandezas sociais, sugerimos o ensaio teoricamente mais didático de Marcelo Rede (2012). 
institucionais externas fornecem informações quanto ao estabelecimento de clientelismo e critérios de manutenção dos "pequenos reis" submetidos ao protetorado, o que transmite a imagem dos faraós como reis universais, pois não tratam apenas de questões nacionais. Essa universalidade favorece o tipo de biografia assemelhada aos próprios anais do reino, e ambos conectam-se historicamente. Favoravelmente está a informação única, a descrição pessoal mesmo quando se trata de correspondência oficial e o acontecimento como critério do gênero narrativo. Em adição, não fica evidente a prática de um historiador nos anais, mesmo considerando certas elaborações literárias; temos escribas de acontecimentos, cuja exaltação do rei torna-se imprescindível, e epistolários que consideram a situação social e a análise política conjuntural.

Tomando as manifestações políticas, os anais como narração da vida de indivíduos diferem, sob esta perspectiva, da historiografia quanto à obtenção dos fatos. Enquanto Plutarco, por exemplo, obtém os fatos por intermédio da pesquisa (SILVA, 2006: 54), os autores dos anais colocam-se como testemunhas oculares, fontes do acontecimento, como quem intervêm no desenvolvimento da história, sem descrever algo baseado em fontes orais ou literárias, pois o que deve permanecer são as imagens grandiosas nunca como memória de quem viveu, mas de quem vive. No entanto, Plutarco diferenciou biografia e história.

Para o nosso autor, os acontecimentos dignos de memória, ou seja, as inúmeras guerras de que Alexandre participou, seriam, por se tratarem de fatos inúmeros $e$ grandiosos, a temática tocante ao gênero historiográfico. Plutarco justificou para o seu público, conhecedor da história do rei, a ausência de registros sobre as grandes batalhas que foram preservadas pela tradição e que envolveram a coletividade, afirmando que escrevia biografias, isto é, fatos sobre a vida de um indivíduo (SILVA, 2006: 55).

Plutarco conferia forma biográfica a conteúdos denominados históricos, ainda que tematizando de modo contrastante com os historiadores gregos, especificamente a historiografia das guerras, que conferem dignidade discursiva. Assim como as biografias contextualizam suas personagens, os anais, no que tange ao método, procedem igualmente, mormente em relação ao faraó, interagindo dialeticamente conforme os acontecimentos e, não raro, analisando a conjuntura. Mesmo quando idealizam eventos e personagens reais, os anais preservam a realidade evidente, procedimento que aproxima o epigrafista do métier d'historien.

Uma historiografia como uma pesquisa da história deve emergir de uma investigação que possibilite, sobretudo em sua base de critérios, uma hermenêutica histórica própria de seu 
objeto de pesquisa, ou o conceito de história como lugar interpretativo privilegiado. $\mathrm{O}$ arqueólogo Gian Luigi Prato (2010: 14) afirma que "un'ermeneutica storica, infatti, può sempre confrontare la propria concezione storiografica con quella più o meno implicita nel documento che essa analizza". ${ }^{9}$ A pesquisa deverá considerar a ideia da história como lugar privilegiado da revelação divina, isto não é mais que uma concessão historiográfica comum do antigo Oriente Próximo (PRATO, 2010: 15), o que pode ser aplicado talvez de maneira especial com relação ao Egito e ao faraó. Porquanto, a demonstração de um evento ou a interpretação de um diálogo não se localiza fora da tradição. É bem verdade que não se deve ignorar a possibilidade de criação de conteúdos “orais" nos processos literários. Segundo John van Seters (2008: 66), a transmissão de uma tradição pode ocorrer em um ambiente vital nunca vivido pela personagem central da narração. Essa observação é válida para a escrituração, que subentende um controle, daí as várias etapas e reescrita dos textos; controle demonstrado, inclusive, através da reutilização de tabletes. ${ }^{10}$

\section{Historiografia egípcia}

É bastante mencionarmos que em âmbito grego a história começa com os escritores chamados logógraphoi, que descrevem geograficamente os lugares colonizados pelos gregos. A história propriamente dita começa, portanto, com o logógrafo Hecateu de Mileto, do final do século VI a.C. (JONES, 1997: 306). Caso desejemos apresentar a história como "indagação", então teremos que esperar até Heródoto de Halicarnasso, que faleceu em cerca de 430 a.C. Não é o caso de analisarmos as diferenças entre a escrita da história e especificamente a biografia antiga nesta óptica, mas aqui foi necessário alguma informação.

À medida que descrevemos essas transformações evitou-se absolutizar o discurso e seus efeitos, atentos ao alerta de Ciro Flamarion Cardoso (2012). No entanto, a percepção do texto permite melhor apreensão do objeto e das intenções enunciados que, ao salientar o caráter racional da escrita da história, seguindo postulados construcionistas, torna menos abstratos os objetos sociais. Como o texto historiográfico exige a materialidade do objeto, a interpretação da representação pode dar-se por várias buscas, todas com um efeito não

\footnotetext{
9 Tradução: "Uma hermenêutica histórica, de fato, pode sempre confrontar o próprio conceito historiográfico com aquele mais ou menos implicito no documento que analisa".

10 Muitos documentos epigráficos egípcios, assim como etnografias semíticas, podem ser tomados como comunicação do ponto de vista interpretativo de identificável estamento dominante ou dirigente da sociedade (SANTOS, 2011).
} 
necessariamente gerado ou correspondente à sua intenção e ao seu indício. Há, portanto, razões para acreditar que a história escrita pelo historiador que opera nos domínios em que se articulam a vida social e a materialidade, assim como pelo historiador do discurso, "será fortemente événementielle, porque ele está interessado nos atos efetuados e nos contextos no interior dos quais e sobre os quais eles foram efetuados" (POCOCK, 2003: 68).

No âmbito do Mediterrâneo antigo, a Síria apresenta a inovadora escrita alfabética, cuja afirmação ocorreu com o emprego da escritura ugarítica em textos administrativos (LIVERANI, 2009: 570). Como ato efetuado, a escrita, entendida por Mario Liverani (2009: 128) como "il coronamento del processo di specializzazione lavorativa", 11 foi destinada desde o início, resultando em obras de seleção e ordenamento da realidade com a finalidade de ser transmitido um novo modo de compreender e enfrentar o mundo, portanto algo que diz respeito à ideologia da nova sociedade (LIVERANI, 2009: 128-135).

Mas foi o Egito antigo a sociedade que testemunhou o maior zelo pela conservação dos registros, listas e anais, demonstrando sempre de forma consciente a ideologia real na apresentação dos eventos passados (SETERS, 2008: 145). Por causa dessa ideologia, centrada em torno da figura do faraó, torna-se difícil distinguir os eventos verdadeiramente históricos daqueles relatos idealizados de "acontecimentos" criados no contexto dos símbolos de eternização do faraó. Diante desses documentos extremamente propagandísticos, segundo o egiptólogo John Baines (2005: 39), os súditos “aceitavam que o soberano tinha poderes sobrehumanos" ou consideravam a exatidão literal do fato irrelevante.

Nesta altura, podemos enunciar três importantes plataformas para essa "aceitação". A primeira delas é que o Egito antigo, como um Estado antigo, nunca foi uma cidade-Estado; a segunda, consequente, é que mesmo com a existência de conflitos envolvendo várias cidades, causados pelo processo de desenvolvimento urbano, o Egito não passou por crisis envolvendo "pequenos reis", como aconteceu com certa regularidade no Mediterrâneo; a terceira consiste no fato de o Egito não considerar os territórios tomados, mencione-se territórios no $R$ ’bw/Libu, Kiš/Núbia e Kīnahhī/Síria-Palestina, como egípcios.

Tal Estado era politicamente centralizado, marcado por extrema polarização da riqueza, por símbolos da realeza em todo um Egito percebido como uma dualidade geográfica e simbólica, pelo crescimento de uma arquitetura funerária que assegurava o papel contínuo a ser desempenhado pelos reis em um cosmos ordenado e digno, por formas de arte caracteristicamente elitistas e pela escrita (YOFFEE, 2013: 85).

\footnotetext{
${ }^{11}$ Tradução da citação de Liverani: "o coroamento do processo de especialização do trabalho". 
Além disso, uma cidade-Estado é um microestado institucionalizado e centralizado, portanto murada e com seus próprios estratos, palacianos, leis, guarnições e divisão do trabalho social. Raramente tomado por implosões políticas, o Egito antigo manteve desde o início a padronização da hierarquia e da cultura material desde o Delta, a organização política e a unificação territorial. Quando aborda o Egito em sua importante obra, Norman Yoffee (2013: 87) apõe uma asserção indiciária apropositada às nossas evidências: o "meio ambiente ecologicamente uniforme do Vale do Nilo, da concentração dos mais importantes recursos no interior das fronteiras do Egito e do excelente meio de transporte proporcionado pelo rio Nilo", além da população relativamente pequena.

Ancorados nesta arqueologia histórica, sublinhamos, com efeito, os detalhes da categorização de "histórico" e "não histórico" apresentados quanto ao pensée de l'histoire "do Ser” por François Châtelet. Para Châtelet (Tome 2, 1996: 394-397), deve-se conceituar a historicidade como dimensão omnitemporal do ser e não como elaboração de uma vontade, propondo quanto ao "fazer da história da cultura" não um conjunto de decisões livres, mas a consideração da situação, sua evolução e a perspectiva histórica nos termos dos eventos datáveis e localizáveis, ou seja, em face de uma situação real na irreversibilidade do curso do tempo e do caráter formador do destino. Para operar este raciocínio, Châtelet partiu da seguinte premissa metodológica: acreditando na realidade do passado, ao atribuir uma estrutura com traços atuais aos fatos devemos ter em conta, "en particulier, qu'en aucune manière, il n'est permis de traiter ce qui s'est passé comme du fictif, comme de l'irréel, que la non-actualité du révolu (et de l'avenir) ne peut en aucune façon être identifiée à sa nonréalité!" (Tome 1, 1996: 11). ${ }^{12}$

Por esse quadro, um procedimento de escrituração, que talvez dificulte uma historicização provável, consiste em flexibilizar a interpretação do fenômeno presenciado e as fontes, copiadas segundo a finalidade do registro, como estimular a sua própria aceitação (aceitação do autor ou do sujeito biografado) por parte dos deuses e do povo, armazenar informações, proceder à memorização, mas ainda permitir a retificação em parte do registro; então, o documento torna-se um monumento (LE GOFF, 2012: 414-415). O fato de a escrita no Egito desenvolver-se na esfera da economia, centrada na organização política e em seus símbolos, fez com que os primeiros monumentos textuais fossem manifestações a serviço do

\footnotetext{
12 Tradução: "Em particular, que não é permitido, de forma alguma, tratar o acontecido como fictício ou irreal, que a não atualidade do que teve lugar (ou terá) não pode ser identificada com a sua não realidade!". 
Estado (ASSMANN, 2010: 155). Isto é resultado do predomínio do Estado que não é apenas o garantidor da paz, da ordem e da justiça, mas meio de imortalidade ao indivíduo após a morte.

Ao lado das inscrições reais, descobertas em escritas cuneiformes e hieroglíficas, existem várias inscrições particulares produzidas no Império Antigo (III dinastia, século XXVIII a.C., - XI dinastia, século XX a.C.), cujas obras são mais úteis ao historiador do que as inscrições reais, pois, ao contrário destas, elas relatam acontecimentos políticos. Os chefes de expedições e seus oficiais registravam geralmente como tinham cumprido a sua missão. Poderiam comparar as conquistas da sua expedição às conquistas da expedição anterior, ou seja, de outras autoridades.

No que se refere às homenagens eletivas, "outro tipo de monumento real digno de nota são os relevos dos templos mortuários que retratavam a vida e as atividades do rei. Em parte biográficos e em parte típicos, eles não tinham a única finalidade de celebrar os acontecimentos históricos" (SETERS, 2008: 156). Não obstante, como constatamos supra, nos documentos egípcios defrontamo-nos com a dificuldade de distinguir os verdadeiros eventos dos eventos que se tornaram ideais faraônicos e foram copiados como propaganda posterior em benefício de faraós, refletindo ora ideologia, ora prospectiva dinástica.

Os textos biográficos em estelas e outros monumentos, que formam o maior gênero conservado de excelentes escritos egipcios, recorreram a formulações estreitamente literárias e também exerceram profunda influência em instruções literárias. Essa intertextualidade, que faria pouco sentido se as declarações legalistas fossem lidas literalmente, e não literariamente, relativiza as declarações extremas do panegírico (BAINES, 2005: 37).

No imaginário egípcio, ao ler o acontecimento este como tal passa a tomar vida (acontecer!), uma operação que remete-lhe autonomia, sub-repticiamente alterada, antes da monumentalidade do que descreve. Esta perspectiva cognoscitiva da presença do evento, da coisa, será posta entre os gregos, como evolução cultural, só no século VI a.C.

As póleis reconheciam aqueles homens que sabiam fazer as coisas. Entre estes homens estavam os sábios, o que hoje chamaríamos de filósofos, que também privilegiaram o ver. Desta forma, podemos dizer que a comunicação oral dos poetas e o seu saber por ouvir e memorizar tiveram oposição, a partir do VI século a.C., daqueles que priorizavam o ver. Para estes, o que se conhece pelo ouvir pode produzir ilusões; ao contrário, o ver fundamenta a validade do relato descritivo ou mesmo do explicativo

Em Tempo de Histórias

Publicação do Programa de Pós-Graduação em História da Universidade de Brasília (PPGHIS/UnB)

$\mathrm{N}^{\circ}$. 23, Brasília, ago. - dez. 2013. ISSN 2316-1191 
(THEML, 2002: 14-15).

Em adição, os egípcios antes entenderam que em meio às construções de cidades, palácios e templos deveria haver espaço físico para os relatos, algo irrealizável caso a comunicação oral não fosse fixada documentalmente em forma de anais, que têm ainda o poder de responder à exigência da presença do objeto da escrituração.

\section{Os anais como modelo}

Acerca dessa fixação documental, o templo mortuário tornou-se o espaço privilegiado para as escritas hieroglíficas, sendo que "no Egito antigo as estelas

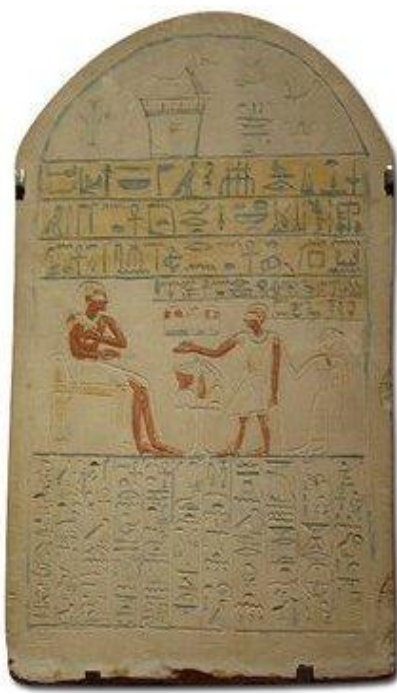

Figura 1: Estela hieroglífica funerária egípcia (Ashmolean Museum, Oxford/UK) desempenharam múltiplas funções de perpetuação de uma memória" (LE GOFF, 2012: 414). Consequentemente, “os hieróglifos são reservados, sobretudo, para as inscrições lapidares e, de modo geral, para as inscrições murais, gravadas, entalhadas ou pintadas" (GRIMAL, 2012: 30). Nesses textos o primeiro aspecto fundamental era a relação do morto com o rei, serviços executados em favor do rei e como conseguiu honrarias; escritos legislativos, morais (ele não roubou o pobre, ajudou, construiu etc.), dentre outros. O segundo aspecto fundamental era a importância da vida após a morte. A biografia procura representar os aspectos favoráveis do morto, "a fim de influenciar não só os deuses, mas também os homens, na esperança de que eles fizessem oferendas constantes ao seu culto funerário" (SETERS, 2008: 197).

Os documentos textuais que demonstram o desenvolvimento da historiografia egípcia não estão nas lápides, mas nas inscrições comemorativas e nos anais. No século XII a.C. já encontramos a Estória de Sinuhe, um clássico da literatura egípcia antiga, ainda que não seja prudente tomar o registro dessa estela como a batalha original envolvendo os líbios (RITNER, 2009: 45; BAINES, 2005: 29 et cetera). No entanto, a escrita biográfica realmente mais conhecida é a biografia tumular, que afirma a eternidade da autoridade. "As biografias tumulares e as inscrições reais compartilham a mesma terminologia. Ambas se dirigem constantemente ao povo egípcio e às gerações futuras e pedem que eles apreciem os grandes feitos e as obras caridosas da pessoa. Ambas insistem em afirmar que a inscrição representa a mais pura verdade" (SETERS, 2008: 200). A este propósito, dentre os objetos funerários 
decorativos, contam as iconografias, esculturas e inscrições para as divindades. ${ }^{13}$

No que diz respeito à escrituração do evento, a mesma deixa consignada a prática política, estabelecendo tanto os tratos diplomáticos quanto as linguagens de poder que escalonam os governantes segundo a importância político-econômica e geográfica do Estado, relativamente aos interesses estratégicos regionais que estiverem em jogo. Por esta característica, é possível contar os "grandes reis" e "pequenos reis", respectivamente aliados/“irmãos" e aliados/“vassalos”, e os foras da lei ou "inimigos”, designados 'pr/"pr.w, 'apīrul'abīru, habiru, ${ }^{14}$ nos documentos de Tell el-'Amarna. Não obstante a variada correspondência do período amarniano, em recente artigo Liliane Cristina Coelho (2013: 18) fornece-nos a importante informação, ainda que em caráter dubitativo, de que "não foram

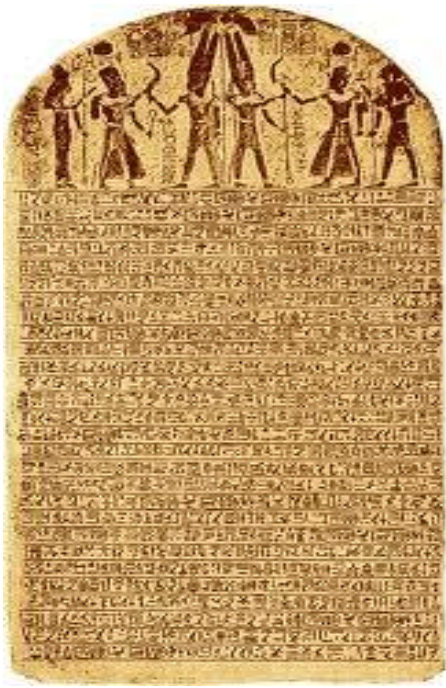

Figura 2: Estela hieroglífica do faraó Merenptah (Biblical Archaeology Review) encontrados tratados firmados entre o Egito e seus vassalos", tratamento que, aliás, não difere com relação àqueles grandes reis coetâneos.

Da importância da documentação oficial não se separam os dados pessoais, evidentemente. Convém não olvidar que Ramsés II introduziu o relevo pictórico ao relato de expedições, com a finalidade de registrar detalhadamente um evento. Os relatos eram copiados e guardados em templos, nas versões Boletim ou Registro e Poema. As obras podem ser edições mais e menos extensas, versão simplificada e obras complementares que devem ser analisadas conjuntamente. Na corte do faraó Merenptah (1213-1203 a.C.), ${ }^{15}$ filho e sucessor do faraó Ramsés II (1279-1213 a.C.), registrava-se os eventos em verso e em prosa. Exemplo de narrativa com conteúdo biográfico é a estela Hino da vitória de Merenptah, Cairo e Karnak ("estela do faraó Merenptah").

$O$ hábito de registrar o mesmo acontecimento em verso [e] em prosa se faz sentir na corte de Merenptah (1224-1214 a.C.). Existe um relato em prosa sobre a invasão dos líbios e dos povos do mar durante o quinto ano do reinado de Merenptah, que contém uma longa introdução e uma conclusão com dois discursos autolaudatórios proferidos pelo rei e repletos de expressões estereotipadas. Ao contrário da Batalha de Kadesh, não descreve com precisão a cena da batalha e a qualidade do relato é bem inferior. A

\footnotetext{
${ }^{13}$ As fontes catalogadas podem ser conferidas na obra dirigida por Kenneth A. Kitchen (2000: 25).

${ }^{14}$ Para um estudo comparativo sobre este e outros grupos populacionais, cf. nosso artigo (SANTOS, 2013b).

${ }^{15}$ Adotamos a datação do egiptólogo Nicolas Grimal. 
versão poética, após mencionar a data, os títulos do rei e o panegírico formal [discurso em louvor do faraó], não faz nenhum tipo de contextualização em prosa e envereda imediatamente pela descrição da derrota. Quanto à técnica poética, o texto se assemelha ao Poema de Kadesh, mas nem se compara a este texto quanto ao uso da narração épica, na medida em que apresenta apenas uma sequência de cenas em detrimento da verdadeira ação. Depois da descrição inicial da devastação da Líbia, há uma cena sobre a corte divina antes do início da batalha. Aqui Merenptah é nomeado guardião da justiça e recebe a espada de Ptá, enquanto o chefe da Líbia é condenado por seus crimes contra os locais sagrados. A guerra significa, assim, uma provocação, na qual os culpados seriam punidos. É importante notar que este tema ocorre entre os hititas e assírios aproximadamente na mesma época. A cena final mostra a situação tranquila do Egito depois da vitória (SETERS, 2008: 171-172).

O hino apresenta uma estrutura literária com as cenas iniciais à maneira de cabeçalho e a descrição quase sumária da batalha vitoriosa contra os líbios. ${ }^{16}$ Chamamos atenção para o fato de que a citação referente aos

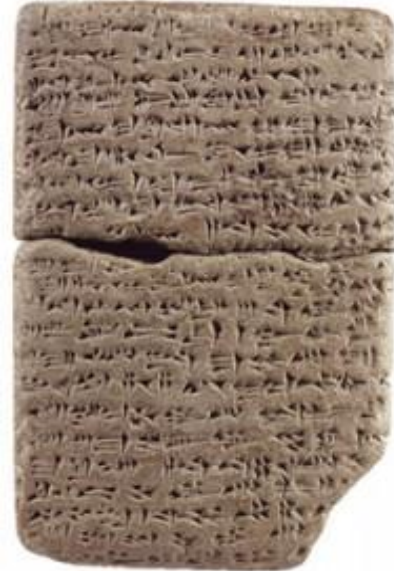

Figura 3: Tablete cuneiforme de Amarna (Bildarchiv Preussischer Kulturbesitz-Art Resource, NY/USA)

Estados e ao grupo populacional está no contexto de uma completa aniquilação de povos e cidades. Reconhecidamente, o âmbito é o da linguagem do Mediterrâneo antigo (RAINEY, 2001: 64). Ademais, em todas as inscrições em Karnak acerca da campanha de Merenptah, em seu quinto ano de reinado, contra a coalisão de tribos, da Líbia em direção à fronteira do Delta, a linguagem assemelha-se; vice-versa, a epigrafia dificulta, como observou Robert Ritner (2009: 47-48), "to wonder whether these statements describe real punitive acts by Egyptians in the Libyan heartlands or are simply a theological explanation of the famine that drove the Libyans to the Egyptian frontier". ${ }^{17}$ Nos casos analisados, temos o modelo imposto pelo Império Egípcio tanto à maneira de intimidação como de exibição de superioridade aos colonizados, vassalos e rebeldes ou "inimigos".

Por outros sujeitos e circunstâncias o teor da escrita muda completamente. Podemos verificar o estilo entre o biográfico e a simples apresentação no cabeçalho das correspondência com caráter de reciprocidade entre os grandes reis acerca de homenagens, presentes, proteção de representantes e pedidos de ouro sem finalidade mercantil, nem sempre

\footnotetext{
${ }^{16}$ Tomamos como fonte documental a inscrição completa da estela editada por Kenneth A. Kitchen (2003: 1015). Para um estudo linguístico da estela, sugerimos a pesquisa produzida por Anson F. Rainey (2001: 57-75).

${ }^{17}$ Tradução: "Para saber se estas declarações descrevem atos punitivos reais pelos egípcios no centro da Líbia ou são simplesmente uma explicação teológica da fome que levou os líbios à fronteira egípcia”.
} 
com a fórmula de submetimento "o sol, meu senhor" ou "ao rei meu senhor, meu deus, meu sol".

Em face do que acabamos de afirmar, atestamos alguns exemplos e parte do conteúdo característico de vários documentos amarnianos: EA 5; 7; 8: "Como um presente eu vou trazer uma mina de lazulite. Envia o meu menssageiro, pois eu estou ciente da saúde de meu irmão"; 13; 14; 19; 22; 147. O mesmo pode ser constatado onde há demonstração de ressentimento, como na carta de Burna-Buriaš, rei de Babilônia, ao faraó Amenhotep IV (EA 9: “Agora, [se] o ouro é abundante, manda-me na mesma quantidade do meu pai, se é escasso, manda-me [pelo menos] metade da quantidade do meu pai! Por que você me mandou [só] duas minas de ouro?”), ou reclamação acerca de determinado dom, como na carta do rei Ašuruballit, rei de Aššur, ao faraó Amenhotep IV (EA 16: “O envio de um grande rei é isto?”). ${ }^{18}$ Há, inclusive, uma placa de prata com gentileza consignada, da época do faraó Ramsés II, na capital hitita de Hattuša, anunciando um acordo de paz (PEYRONEL, 2008: 152; SANTOS, 2013a: 90-100). Linguagem correlativa pode ser encontrada impressa na decoração dos túmulos dos palacianos com pinturas e relevos que representavam retratos de família, ao lado das cenas inscreviam-se relatos autobiográficos e obituários com poucas informações históricas.

A pertinência entre os anais e a biografia antiga tem atestação não apenas em inscrições egípcias, mas também entre os hititas; ambos comumente faziam constar nas biografias os tratados de vassalagem, em que um rei morto deixa escrito que reconhece o rei de um Estado vassalo ou de uma colônia e exige do seu sucessor ou herdeiro a continuidade da relação entre os dois povos. Para bem precisar os testemunhos arqueológicos, nos marcos das interações culturais e experiências coloniais do Egito no Mediterrâneo, no Bronze Recente, os túmulos de funcionários reais egípcios em Gebal/Biblos demonstram a importância das inscrições memoriais, ora com a descrição das aventuras do morto como agente real no estrangeiro, ora aludindo às celebrações em honra dos faraós - neste caso, segundo María Eugenia Aubet (2007: 290), “implica la presencia en la ciudad de sacerdotes y especialistas del culto dedicados a atender las necesidades religiosas de los residentes egipcios”. Interpretando a escassez de informação histórica, John van Seters (2008: 196-197) afirmou com justeza que as biografias constituem as mais importantes fontes do Império Egípcio. A partir da VI dinastia (2460-2200 a.C.), as inscrições tumulares tornaram-se

\footnotetext{
${ }^{18}$ Para a análise e tradução dos mencionados documentos de Tell el- 'Amarna consultamos a obra editada em dois volumes por Mario Liverani (1998; 1999).
} 
autobiográficas.

\section{Considerações finais}

Sugerimos a abordagem comparativa em torno dos registros de acontecimentos egípcios para propor debates pertinentes às experiências históricas e sua recepção, mormente as relações de poder locais e internacionais. Acerca da diplomacia, fazemos alusão porque em muito contribuem os detalhes dos documentos textuais para o entendimento da política externa e seus representantes nas operações das guarnições egípcias (SANTOS, 2012). Em adição, a supremacia absoluta do faraó possibilitou a relativização do conhecimento histórico - em suas potencialidades racionais -, mas não conseguiu impedir completamente as relações privadas mesmo no âmbito religioso.

Enfim, entendemos que é razoável considerar as evidências epigráficas que demonstram que os egípcios não se anteciparam aos gregos apenas quanto à historiografia dos eventos, mas, em algum grau, anteciparam a avaliação da própria História.

\section{Referências bibliográficas}

ASSMANN, Jan. La mémoire culturelle: écriture, souvenir et imaginaire politique dans les civilisations antiques. Paris: Éditions Flammarion, 2010.

AUBET, María Eugenia. Comercio y colonialismo en el Próximo Oriente antiguo: los antecedentes coloniales del III y II milenios a.C. Barcelona: Edicions Bellaterra, 2007.

BAINES, John. "A realeza egípcia antiga: formas oficiais, retórica, contexto". In: DAY, John (Org.). Rei $e$ messias em Israel e no antigo Oriente Próximo. São Paulo: Paulinas, 2005, p. 19-56.

CARDOSO, Ciro Flamarion. "História e textualidade". In: CARDOSO, Ciro Flamarion; VAINFAS, Ronaldo (Orgs.). Novos domínios da história. Rio de Janeiro: Elsevier, 2012, p. 225-241.

CERTEAU, Michel de. A escrita da história. 3. ed. Rio de Janeiro: Forense Universitária, 2011.

CHÂTELET, François. La naissance de l'histoire. Tome 1. Paris: Éditions de Minuit, 1996.

CHÂTELET, François. La naissance de l'histoire. Tome 2. Paris: Éditions de Minuit, 1996.

COELHO, Liliane Cristina. "O Egito e seus vizinhos: relações de poder nas Cartas de Amarna". In: BIRRO, Renan M.; CAMPOS, Carlos Eduardo da Costa (Orgs.). Relações de poder: da Antiguidade ao Medievo. Vitória: Departamento de Letras da Universidade Federal do Espírito Santo, 2013, p. 1-24.

DOSSE, François. O desafio biográfico: escrever uma vida. São Paulo: Editora da Universidade de São Paulo, 2009.

GRENDI, Edoardo. "Paradoxos da história contemporânea". In: OLIVEIRA, Mônica Ribeiro de; ALMEIDA, Carla Maria Carvalho de (Orgs.). Exercícios de micro-história. Rio de Janeiro: Editora da Fundação Getúlio Vargas, 2009, p. 39-49.

GRIMAL, Nicolas. História do Egito antigo. Rio de Janeiro: Forense Universitária, 2012.

JONES, Peter V. "O mundo intelectual”. In: JONES, Peter V. (Org.). O mundo de Atenas: uma introdução à cultura clássica ateniense. São Paulo: Martins Fontes, 1997, p. 283-360.

KITCHEN, Kenneth A. Ramesside inscriptions, translated \& annotated translations. Vol. III: Ramesses II, his contemporaries. Oxford: Wiley- Blackwell, 2000.

KITCHEN, Kenneth A. Ramesside inscriptions: translated \& annotated translations. Vol. IV: Merenptah \& the late Nineteenth Dynasty. Oxford: Wiley-Blackwell, 2003. 
KOSELLECK, Reinhart. Futuro passado: contribuição à semântica dos tempos históricos. Rio de Janeiro: Editora Contraponto; Editora da Pontifícia Universidade Católica, 2011.

LE GOFF, Jacques. História e memória. 6. ed. Campinas: Editora da Universidade Estadual de Campinas, 2012. LIVERANI, Mario. Le lettere di el-Amarna. Vol 1: Le lettere dei "Piccoli Re". Brescia: Paideia Editrice, 1998. LIVERANI, Mario. Le lettere di el-Amarna. Vol. 2: Le lettere dei "Grandi Re”. Brescia: Paideia Editrice, 1999. LIVERANI, Mario. Antico Oriente: storia, società, economia. 8. ed. Roma; Bari: Editori Laterza, 2009.

MOMIGLIANO, Arnaldo. Problèmes d'historiographie ancienne et moderne. Paris: Éditions Gallimard, 1983. MORRISON, Kathleen D. "Sources, approaches, definitions". In: ALCOCK, Susan E. et al. (Orgs.). Empires: perspectives from archaeology and history. Cambridge: Cambridge University Press, 2009, p. 1-9.

PEYRONEL, Luca. Storia e archeologia del commercio nell'Oriente antico. Roma: Carocci Editore, 2008.

POCOCK, John G.A. Linguagens do ideário político. São Paulo: Editora da Universidade de São Paulo, 2003.

PORTER, Anne. "Beyond dimorphism: ideologies and materialities of kinship as time-space distanciation". In: SZUCHMAN, Jeffrey (Ed.). Nomads, tribes, and the State in the ancient Near East: cross-disciplinary perspectives. Chicago: The Oriental Institute of the University of Chicago, 2009, p. 201-225.

PRATO, Gian Luigi. Identità e memoria nell'Israele antico: storiografia e confronto culturale negli scritti biblici e giudaici. Brescia: Paideia Editrici, 2010.

RAINEY, Anson F. "Israel in Merenptah's Inscription and Reliefs". Israel Exploration Journal, Jerusalem, v. 51, n. 1, p. 57-75, 2001.

REDE, Marcelo. "História e cultura material". In: CARDOSO, Ciro Flamarion; VAINFAS, Ronaldo (Orgs.). Novos domínios da história. Rio de Janeiro: Elsevier, 2012, p. 133-150.

RITNER, Robert. "Egypt and the vanishing Libyan: institutional responses to a nomadic people". In: SZUCHMAN, Jeffrey (Ed.). Nomads, tribes, and the State in the ancient Near East: cross-disciplinary perspectives. Chicago: The Oriental Institute of the University of Chicago, 2009, p. 43-56.

SANTOS, João Batista Ribeiro. "No princípio eram os escravos: a etnografia hebraica e as fontes epigráficas egípcias sobre a origem mediterrânea do antigo Israel”. Cadernos de História, Mariana, v. 6, n. 2, p. 12-26, 2011.

SANTOS, João Batista Ribeiro. “A experiência do mundo: uma visão historiográfica sobre a cidade de Gaza no contexto da materialidade do Mediterrâneo antigo”. Diálogos, Maringá, v. 16, n. 3, p. 951-969, 2012.

SANTOS, João Batista Ribeiro. A emergência do antigo Israel: um diálogo entre a história e a arqueologia histórica na busca da identidade étnica da grandeza social "Israel" no Mediterrâneo nos séculos XIV-XIII a.C. Dissertação de Mestrado. Rio de Janeiro: Instituto de Filosofia e Ciências Humanas da Universidade do Estado do Rio de Janeiro, 2013a.

SANTOS, João Batista Ribeiro. "Os povos da terra. Abordagem historiográfica de grandezas sociais do antigo Oriente-Próximo no segundo milênio a.C.: uma apresentação comparativa”. Revista Caminhando, São Bernardo do Campo, v. 18, n. 1, p. 125-136, 2013 b.

SETERS, John van. Em busca da história: historiografia no mundo antigo e as origens da história bíblica. São Paulo: Editora da Universidade de São Paulo, 2008.

SILVA, Maria Aparecida de Oliveira. Plutarco historiador: análise das biografias espartanas. São Paulo: Editora da Universidade de São Paulo, 2006.

THEML, Neyde. "Linguagem e comunicação: ver e ouvir na Antiguidade". In: THEML, Neyde (Org.). Linguagens e formas de poder na Antiguidade. Rio de Janeiro: Mauad; FAPERJ, 2002, p. 11-24.

YOFFEE, Norman. Mitos do Estado arcaico: evolução dos primeiros Estados, cidades e civilizações. São Paulo: Editora da Universidade de São Paulo, 2013. 